\title{
Effect of modified Xiaochaihu decoction-containing serum on HepG2.2.15 cells via the JAK2/STAT3 signaling pathway
}

\author{
SHAOFANG CHEN ${ }^{1}$, ZHANGLIN WANG $^{1}$, SHICHUAN WAN $^{1}$, HAI HUANG ${ }^{1}$ and HUIQING LIANG ${ }^{1,2}$ \\ ${ }^{1}$ College of Chinese Medicine, Fujian University of Traditional Chinese Medicine, Fuzhou, Fujian $350122 ;{ }^{2}$ Xiamen Hospital \\ of Traditional Chinese Medicine, Fujian University of Traditional Chinese Medicine, Xiamen, Fujian 361009, P.R. China
}

Received November 4, 2016; Accepted June 19, 2017

DOI: $10.3892 / \mathrm{mmr} .2017 .7561$

\begin{abstract}
The present study aimed to investigate the possible mechanisms underlying the effect of modified Xiaochaihu decoction (mXCHD) in the treatment of chronic hepatitis $\mathrm{B}(\mathrm{CHB})$. Patients with $\mathrm{CHB}$, in addition to liver stagnation and spleen deficiency syndrome were randomly assigned to receive either Chinese (mXCHD) or western (entecavir) treatment, with 30 cases in each group. Serum was collected following treatment with $\mathrm{mXCHD}$ or entecavir for 7 days. A healthy group of 30 individuals was also included. HepG2.2.15 cells were cultured in vitro and randomly divided into four groups: Healthy; entecavir-treated; $10 \%$ mXCHD-treated; and 20\% mXCHD-treated. The HepG2.2.15 cells in the four groups were treated with either serum from the healthy volunteers, entecavir-containing serum, or $\mathrm{mXCHD}$-containing serum at different concentrations (10 or $20 \%$, respectively). Following treatment with the corresponding serum, cell proliferation was examined using an MTT assay, and the expression of hepatitis B surface antigen (HBsAg) in the cell supernatant was detected using an enzyme-linked immunosorbent assay. The mRNA and protein expression levels of Janus kinase (JAK) 2 and signal transducer and activator of transcription (STAT)3 were measured using reverse transcription-quantitative polymerase chain reaction and western blot analyses, respectively. The results indicated that the most effective treatment for the promotion of HepG2.2.15 cell proliferation was a $20 \%$ concentration of $\mathrm{mXCHD}$ serum. The expression of HBsAg was significantly decreased in the groups treated with 10 and $20 \% \mathrm{mXCHD} 48 \mathrm{~h}$ following intervention $(\mathrm{P}<0.01)$. The mRNA and protein expression levels of STAT3 in the $20 \% \mathrm{mXCHD}$ serum group were significantly increased, compared with those in the healthy group $(\mathrm{P}<0.01$ and $\mathrm{P}<0.05$,
\end{abstract}

Correspondence to: Dr Huiqing Liang, Xiamen Hospital of Traditional Chinese Medicine, Fujian University of Traditional Chinese Medicine, 1739 Xianyue Road, Xiamen, Fujian 361009, P.R. China

E-mail: fjtcm2016@163.com

Key words: Chinese medicine, chronic hepatitis B, HepG2.2.15 cell, Xiaochaihu decoction, human drug-containing serum respectively), whereas no significant difference was observed in the expression of JAK2 among the four groups. These results indicated that $\mathrm{mXCHD}$ suppressed the hepatitis B virus, and treatment of the cells with $\mathrm{mXCHD}$-containing serum promoted HepG2.2.15 cell proliferation via modulating the expression of STAT3, which may contribute to the clinical efficacy of $\mathrm{mXCHD}$ against $\mathrm{CHB}$.

\section{Introduction}

Hepatitis $\mathrm{B}$ is the most common serious liver infection worldwide. Chronic hepatitis $\mathrm{B}(\mathrm{CHB})$ is a major public health concern, affecting 240,000,000 individuals with chronically infection, and leading to $\sim 650,000$ individuals each year succumbing to CHB-associated mortality worldwide (1). The major complications of $\mathrm{CHB}$ are cirrhosis and hepatocellular carcinoma (HCC) $(2,3)$. Antiviral agents with activity against hepatitis B virus (HBV) are available. CHB can be treated with drugs, including interferons, and antiviral agents, including nucleos(t)ide analogue (NA), which have been shown to suppress HBV replication, prevent its progression to cirrhosis, and reduce the risk of HCC (4). However, current available treatment methods fail to eradicate the virus in the majority of those treated. In addition, long-term NA therapy does not guarantee protection against the development of HCC or $\mathrm{CBH}$-associated mortality in patients with cirrhosis (5).

Traditional Chinese medicine (TCM) is widely used in China and is becoming increasingly prevalent in Europe and America. Since $\sim 1950$, the scientific evaluation of herbs used for the treatment of viral hepatitis has been undertaken in China, including clinical investigations of complex formulas and isolated components, isolation of active constituents, and assessment of crude herb extracts and purified components in laboratory animals. Several complex formulas and crude materials used in Chinese medicines have been shown to have measurable activity against viral hepatitis, including Xiaochaihu decoction (XCHD) (6-8).

$\mathrm{XCHD}$, a TCM clinical prescription, has advanced the treatment of hepatobiliary diseases in China $(9,10)$. Modified XCHD (mXCHD) has been used to treat $\mathrm{CHB}$ and has shown clinical efficacy (11,12). XCHD is supplemented with Phyllanthus urinaria (YeXiaZhu in Chinese), Largehead atractylodes rhizome (BaiZhu in Chinese), Poria cocos (FuLing in Chinese), white peony root (BaiShao in Chinese) and Fructus Schisandrae (WuWeiZi in Chinese) to produce mXCHD. 
In clinical trials performed in China during the last 20 years, the standards of effectiveness have usually comprised a reduction in the serum levels of alanine transaminase (ALT) and aspartate transaminase (AST) liver enzymes and HBV DNA, and seroconversion from hepatitis B surface antigen $(\mathrm{HBsAg})^{+}$ or hepatitis $\mathrm{B}$ e antigen $\left(\mathrm{HBeAg}^{+}\right.$to $\mathrm{HBsAg}^{-}$and $\mathrm{HBeAg}^{-}$, in addition to various measures of symptom reduction. The actions of XCHD may be subdivided into two categories: Hepatoprotective and antiviral (13-18).

To further elucidate the possible molecular mechanism underlying the effect of $\mathrm{mXCHD}$ in the treatment of $\mathrm{CHB}$, a serum pharmacological method was used in the present study to investigate the effects of $\mathrm{mXCHD}$ on the proliferation of HepG2.2.15 cells, and on factors associated with the Janus kinase (JAK)2/signal transducer and activator of transcription (STAT)3 signaling pathway in vitro.

\section{Materials and methods}

Materials and reagents. Minimum essential medium (MEM), fetal bovine serum (FBS), sodium pyruvate, penicillin-streptomycin, sodium bicarbonate solution and trypsin-EDTA were purchased from Thermo Fisher Scientific, Inc. (Waltham, MA, USA). RNA Isolater Total RNA Extraction Reagent, HiScript ${ }^{\circledR}$ II Q RT Supermix for qPCR (+gDNA wiper), AceQ ${ }^{\circledR}$ qPCR SYBR ${ }^{\circledR}$-Green Master Mix, RIPA lysis buffer and a BCA protein quantification kit were obtained from Vazyme Biotech Co., Ltd. (Nanjing, China). The following antibodies were purchased from ProteinTech Group, Inc. (Chicago, IL, USA): JAK2 polyclonal antibody, STAT3 monoclonal antibody, and $\beta$-actin monoclonal antibody. Secondary antibodies, including horseradish peroxidase (HRP)-conjugated goat anti-rabbit $\operatorname{IgG}(\mathrm{H}+\mathrm{L})$ and HRP-conjugated goat anti-mouse IgG $(\mathrm{H}+\mathrm{L})$, were obtained from Vazyme Biotech Co., Ltd.

Participants. The participants involved in the present study were recruited among volunteers receiving a physical check-up, outpatients and inpatients between January 2015 and May 2015 at the Second Affiliated Hospital of the Fujian University of Traditional Chinese Medicine (Fuzhou, China; 30 cases and 30 healthy volunteers) and Xiamen Hospital of Traditional Chinese Medicine (Xiamen, China; 30 cases).

Diagnosis, inclusion and exclusion criteria for CHB and TCM differentiation. CHB was diagnosed according to the Guideline of Prevention and Treatment for Chronic Hepatitis B (19) established by the Chinese Society of Hepatology and Chinese Society of Infectious Diseases of the Chinese Medical Association. The inclusion criteria for $\mathrm{CHB}$ were as follows: Meets the diagnostic criteria of $\mathrm{CHB}$; provision of a signed informed consent form; age range between 18 and 60 years old. The exclusion criteria were as follows: Cases of $\mathrm{CHB}$ combined with another hepatitis virus; cases of chronic severe hepatitis and cirrhosis; pregnant or lactating women; and individuals unable to express their feelings clearly.

The standards of the liver stagnation and spleen deficiency syndrome (LSSDS) for the use of TCMs in CHB were as defined in the TCM syndrome differentiation standards of viral hepatitis (Trial) (20) issued by the Internal Medicine
Department Committee of Liver Disease of the Traditional Chinese Medicine Association. The major features include distending pain of the lateral thorax, and abdominal distension and loose stools. The minor features include chest distress and depression, lassitude and fatigue, and a pink and tooth-marked tongue. The inclusion criteria for LSSDS were as follows: Cases with all major features; cases with the major feature of chest distress and depression, and the minor features of lassitude and fatigue, and a pink and tooth-marked tongue; and cases with the major feature of abdominal distension and loose stools, and the minor feature of chest distress and depression.

Ethics and consent. The study protocol conformed to the Helsinki Declaration (21) and the research regulations for Chinese clinical trials. The Ethics Committee of Fujian University of Traditional Chinese Medicine reviewed and approved the study protocol, and all participants signed informed consent prior to participation in the study. Patients with $\mathrm{CHB}$, who met the LSSDS diagnostic criteria and were enrolled. All patients were randomly divided into the $\mathrm{mXCHD}$ group and the western medicine group, with 30 patients in each group.

Preparation of drugs. The components of XCHD and mXCHD are listed in Table I. The Chinese herbs were processed into formula granules at Beijing Tcmages Pharmaceutical Co., Ltd. (Beijing, China). The production procedure was as follows: Selection of the genuine regional drug; implementation of modern pharmaceutical technology; use of Chinese herbal fragments as raw materials according to traditional processing methods; preparation of the granular formulation following single-herb extraction; concentration and drying with the decoction as a standard. As presented in Table II, the quality of the granules met the Codex standard for enterprise internal control standards (22).

Preparation of $m X C H D$-containing serum. The participants in the $\mathrm{mXCHD}$ group were treated with $\mathrm{mXCHD}$ (Table I) twice a day, using one bag (10 g) each time, 30 min following breakfast and dinner. The patients in the western medicine group were treated with $0.5 \mathrm{mg}$ of entecavir orally as a dispersible tablet (Chiatai Tianqing Pharmaceutical Group, Lianyungang, China; cat. no. 141226201) daily. After 7 days, venous blood was obtained from all individuals. An additiona 130 healthy volunteers donated their venous blood for the study as a control. The sera were separated by centrifugation at $1,006 \mathrm{xg}$ at room temperature for $5 \mathrm{~min}$ and stored at $-80^{\circ} \mathrm{C}$.

Cell culture. The HepG2.2.15 human hepatoma cell line stably transfected with the HBV genome was obtained from the China Center for Type Culture Collection (Wuhan, China). The cells were maintained in MEM supplemented with $10 \%$ (vol/vol) FBS (Thermo Fisher Scientific, Inc.), $1 \mu \mathrm{mol} / \mathrm{ml}$ sodium pyruvate (Thermo Fisher Scientific, Inc.), $100 \mathrm{U} / \mathrm{ml}$ penicillin and $100 \mu \mathrm{g} / \mathrm{ml}$ streptomycin (Thermo Fisher Scientific, Inc.), adjusted to $\mathrm{pH} 7-7.2$ with $7.5 \%$ sodium bicarbonate. A humidified incubator with $5 \% \mathrm{CO}_{2}$ was used to maintain the cells at $37^{\circ} \mathrm{C}$.

Cell treatment and grouping. The HepG2.2.15 cells were randomly divided into the following four groups: Healthy group, entecavir group, $10 \% \mathrm{mXCHD}$ group and $20 \% \mathrm{mXCHD}$ 
Table I. Components of XCHD and mXCHD.

\begin{tabular}{|c|c|c|c|c|}
\hline $\begin{array}{l}\text { Chinese } \\
\text { name }\end{array}$ & English name & Scientific name & $\mathrm{mXCHD}(\mathrm{g})$ & $\mathrm{XCHD}(\mathrm{g})$ \\
\hline Chai Hu & Chinese thorowax root & Bupleurum chinense DC & 15 & 15 \\
\hline Huang Qin & Scutellaria baicalensis & Scutellaria baicalensis Georgi. & 10 & 10 \\
\hline Ban Xia & Pinellia ternate & Pinellia ternate (Thunb.) Breit. & 10 & 10 \\
\hline Sheng Jiang & Ginger & Zingiber officinale Rosc. & 10 & 10 \\
\hline Ren Shen & Ginseng & Panax ginseng C. A. Mey. & 10 & 10 \\
\hline Da Zao & Ziziphi Jujubae & Ziziphus Jujubae Mill. var. inermis (Bge.) Rehd. & 10 & 10 \\
\hline Gan Cao & Liquorice root & Radix Glycyrrhizae & 10 & 10 \\
\hline Ye Xia Zhu & Phyllanthus urinaria & Phyllanthus urinaria L. & 15 & - \\
\hline Bai Zhu & Largehead atractylodes rhizomze & Atractylodes macrocephala Koidz. & 15 & - \\
\hline Fu Ling & Poria cocos & Poria cocos (Schw.) Wolf. & 15 & - \\
\hline Bai Shao & White peony root & Paeonia lactiflora Pall. & 10 & - \\
\hline Wu Wei Zi & Fructus schisandrae & Schisandra chinensis (Turcz.) Baill. & 10 & - \\
\hline
\end{tabular}

XCHD, Xiaochaihu decoction; mXCHD, modified XCHD.

Table II. Quality standards of the granules.

\begin{tabular}{llr}
\hline Granule & Active ingredients & Control standard \\
\hline Chinese thorowax root & $95 \%$ ethanol extract & $15 \%$ minimum \\
Pinellia ternate & $95 \%$ ethanol extract & $1 \%$ minimum \\
Ginger & $95 \%$ ethanol extract & $3 \%$ minimum \\
Ziziphi jujubae & $95 \%$ ethanol extract & $20 \%$ minimum \\
Largehead atractylodes rhizome & $95 \%$ ethanol extract & $7 \%$ minimum \\
Poria cocos & $95 \%$ ethanol extract & $1.5 \%$ minimum \\
Scutellaria baicalensis & Baicalin & $10 \%$ minimum \\
Ginseng & Total ginsenoside Rb1 & $0.18 \%$ minimum \\
Liquorice root & Ammonium glycyrrhizinate & $5 \%$ minimum \\
White peony root & Paeoniflorin & $3 \%$ minimum \\
Fructus schisandrae & Schisandrin & $0.03 \%$ minimum \\
Phyllanthus urinaria & Total phenols & $5 \%$ minimum \\
\hline
\end{tabular}

group. The cells of the first three groups were maintained in $10 \%$ (vol/vol) serum, respectively. The cells of the fourth group were maintained in $20 \%$ (vol/vol) mXCHD-containing serum. Following treatment with the appropriate serum, cell proliferation was detected using an MTT assay. The mRNA and protein levels of JAK2 and STAT3 were measured using reverse transcription-quantitative polymerase chain reaction (RT-qPCR) and western blot analyses, respectively.

Determination of HepG2.2.15 cell viability using an MTT assay. The HepG2.2.15 cell suspension was inoculated into a 96-well plate at a density of $4.0 \times 10^{4}$ cells $/ \mathrm{ml}$ in $0.1 \mathrm{ml}$ of medium. The cells were divided into the four groups: Healthy group; entecavir-treated group; 10\% mXCHD-treated group; $20 \%$ mXCHD-treatedgroup. As described above, each group was treated with the indicated human serum. The cells in each group were treated for 48 and $144 \mathrm{~h}$ at $37^{\circ} \mathrm{C}$. At the end of the treatment, $20 \mu \mathrm{l}$ of $5 \mathrm{mg} / \mathrm{ml} \mathrm{MTT}$ was added to each well, and the samples were incubated for an additional $4 \mathrm{~h}$ at $37^{\circ} \mathrm{C}$. The purple/blue MTT formazan precipitate was dissolved in $100 \mu \mathrm{l}$ of dimethylsulfoxide (Sigma-Aldrich; Merck Millipore, Darmstadt, Germany) in each well, and the optical density value of each well was measured at $490 \mathrm{~nm}$ wavelength using an ELISA plate reader (EXL800; BioTek Instruments, Inc., Winooski, VT, USA).

RT-qPCR analysis. The HepG2.2.15 cells were cultured in a 6 -well culture plate (Costar) at a density of $4.0 \times 10^{4}$ cells $/ \mathrm{ml}$ in $2 \mathrm{ml}$ of medium. The grouping of cells was as previously described (healthy, entecavir-treated, 10\% mXCHD-treated, and $20 \%$ mXCHD-treated). Each group was treated with human serum. Following treatment with the appropriate serum for $48 \mathrm{~h}$, the cells in each group were washed with PBS, and the total RNA was isolated using Total RNA Extraction reagent (Vazyme Biotech Co., Ltd.). cDNA was synthesized from $1.5 \mu \mathrm{g}$ of the total RNA using a cDNA synthesis kit 
Table III. Primer sequences.

\begin{tabular}{llcc}
\hline Gene & \multicolumn{1}{c}{ Primer sequence $\left(5^{\prime}-3{ }^{\prime}\right)$} & $\begin{array}{c}\text { Amplicon } \\
\text { length }(\mathrm{bp})\end{array}$ & $\begin{array}{c}\text { Annealing } \\
\text { temperature }\left({ }^{\circ} \mathrm{C}\right)\end{array}$ \\
\hline JAK2 & $\begin{array}{l}\text { Forward: GCCTTCTTTCAGAGCCATCAT } \\
\text { Reverse: GTGTAGGATCCCGGTCTTCAA }\end{array}$ & 143 & 55 \\
STAT3 & $\begin{array}{l}\text { Forward: GGAGGAGGCATTCGGAAAGTA } \\
\text { Reverse: CTGCAGGTCGTTGGTGTCA }\end{array}$ & 120 & 55 \\
-actin & $\begin{array}{l}\text { Forward: CCTGGCACCCAGCACAAT } \\
\text { Reverse: GGGCCGGACTCGTCATAC }\end{array}$ & 156 & 55 \\
\hline
\end{tabular}

JAK2, Janus kinase 2; STAT3, signal transducer and activator of transcription 3.

(Vazyme Biotech Co., Ltd.). RT-qPCR was performed using a 20- $\mu 1$ reaction mixture, which contained $10 \mu \mathrm{l}$ of SYBR-Green Master Mix (Vazyme Biotech Co., Ltd.) and $2 \mu \mathrm{l}$ of cDNA with $0.2 \mu \mathrm{M}$ of each of the forward and reverse primers. The qPCR conditions were as follows: $95^{\circ} \mathrm{C}$ preheating for $5 \mathrm{~min}$, followed by 40 cycles of $95^{\circ} \mathrm{C}$ for $10 \mathrm{sec}$ and $60^{\circ} \mathrm{C}$ for $35 \mathrm{sec}$. To confirm the amplification specificity, each $\mathrm{qPCR}$ product was evaluated by melting curve analysis. The reaction was performed using an Applied Biosystems 7500 FastReal-Time PCR system (Thermo Fisher Scientific, Inc.). The relative expression of the mRNA was calculated using the $2^{-\Delta \Delta C q}$ method (23). $\beta$-actin mRNA was used as an internal standard, and each result was normalized to the level of $\beta$-actin. The sequences of the primers used in the present study are presented in Table III.

Western blot analysis. Following treatment with the medicated serum for $48 \mathrm{~h}$, the HepG2.2 15 cells were lysed with RIPA lysis buffer containing protease and phosphatase inhibitor cocktails (Vazyme Biotech Co., Ltd.). Following centrifugation at $13,000 \mathrm{x}$ f for $15 \mathrm{~min}$ at $4^{\circ} \mathrm{C}$, the supernatants were collected and the total protein content was quantified using a bicinchoninic acid protein assay. Proteins (30 $\mu \mathrm{g}$ per well) were separated by $8 \%$ SDS-PAGE, under the following conditions: $25 \mathrm{~V}$ for $10 \mathrm{~min}, 80 \mathrm{~V}$ for $30 \mathrm{~min}$ and $120 \mathrm{~V}$ for $70 \mathrm{~min}$. Following electrophoresis, the proteins were transferred onto polyvinylidine fluoride membranes (EMD Millipore, Billerica, MA, USA) in 1-Step ${ }^{\mathrm{TM}}$ transfer buffer (Thermo Fisher Scientific Inc.) using a semidry blotting system. The membranes were blocked for $2 \mathrm{~h}$ with western blot blocking buffer (Beyotime Institute of Biotechnology, Shanghai, China). The membranes were then exposed to the primary antibodies against JAK2 (1:2,000; cat. no. 17670-1-AP; ProteinTech Group, Inc.) and STAT3 (1:1,000; cat. no. 60199-1-lg; ProteinTech Group, Inc) overnight at $4^{\circ} \mathrm{C}$. $\beta$-actin (1:1,000; cat. no. 60008-1-1g; ProteinTech Group, Inc) was used as an internal control for protein loading. The membranes were then washed in TBST and incubated with secondary HRP-conjugated antibodies (Vazyme Biotech Co. Ltd; cat. no. SA00001-2) at a 1:5,000 dilution for $1 \mathrm{~h}$ at room temperature, and the membranes were washed again in TBST. Finally, the antibody-bound protein bands were detected using enhanced chemiluminescence, and images were captured using a ChemiDoc $\mathrm{XRS}^{+}$system (Bio-Rad Laboratories, Inc., Hercules, CA, USA). The greyscale value ratio of the target protein to the internal control was used to measure the relative concentrations of JAK2 and STAT3.

Enzyme-linked immunosorbent assay (ELISA). The cell culture supernatants in the four groups were collected immediately and at $48 \mathrm{~h}$ post-intervention, and were separated by centrifugation at $1,006 \mathrm{x} g$ at room temperature for $3 \mathrm{~min}$. The expression of HBsAg in the supernatant was detected using ELISA according to the manufacturer's protocol by determining the absorbance rate at $450 \mathrm{~nm}$.

Statistical analysis. The values are expressed as the mean \pm standard deviation. Statistical analyses of the data were performed using a paired t-test and a one-way analysis of variance with SPSS, version 23.0 (IBM SPSS, Armonk, $\mathrm{NY}$, USA). $\mathrm{P}<0.05$ was considered to indicate a statistically significant difference.

\section{Results}

Effect of $m X C H D$ serum on HepG2.2.15 cell viability. As shown in Fig. 1, HepG2.2.15 cell proliferation was significantly higher in the $20 \% \mathrm{mXCHD}$ serum group in a time-dependent manner $(\mathrm{P}<0.01)$, compared with the healthy group and $10 \% \mathrm{mXCHD}$ group.

Effect of $m X C H D$ serum on the concentration of HBsAg in the cell supernatant. As shown in Fig. 2, treatment with 10 and the $20 \% \mathrm{mXCHD}$ serum led to decreases in the concentration of HBsAg in the supernatants of the HepG2.2.15 cells. The difference between the two time points, immediately following and $48 \mathrm{~h}$ following intervention was significant in the 10 and $20 \% \mathrm{mXCHD}$ groups $(\mathrm{P}<0.01)$. These results suggested that $\mathrm{mXCHD}$ serum inhibited the expression of $\mathrm{HBV}$.

Effect of $m X C H D$ serum on the mRNA expression levels of JAK2 and STAT3 in HepG2.2.15 cells. As shown in Fig. 3, the mRNA expression levels of STAT3 were markedly higher in the 10 and $20 \% \mathrm{mXCHD}$ groups, compared with those in the healthy group $(\mathrm{P}<0.05$ and $\mathrm{P}<0.01)$, whereas no significant differences in JAK2 were observed in the four groups. In the $20 \%$ mXCHD group, the mRNA expression level of STAT3 was higher, compared with that in the entecavir group following treatment for $48 \mathrm{~h}(\mathrm{P}<0.01)$. The mRNA expression 


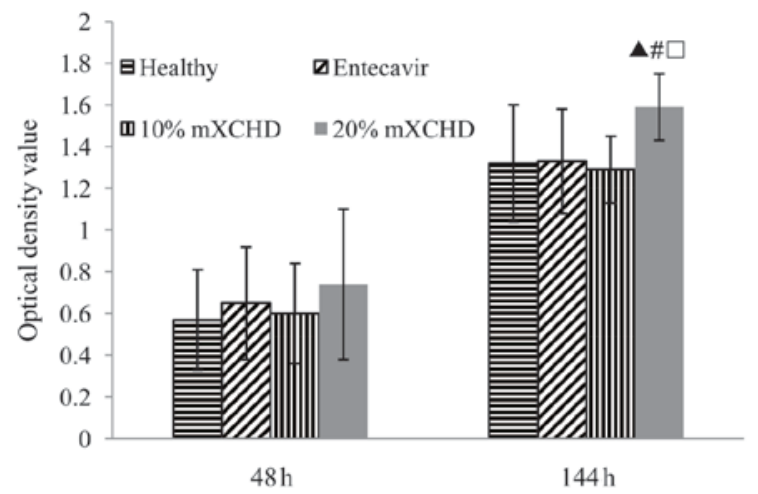

Figure 1. Effect of mXCHD serum on HepG2.2.15 cell viability. Following treatment with different concentrations (10 and 20\%) of mXCHD serum for 48 and $144 \mathrm{~h}$, cell viability was determined using an MTT assay. The data are presented as the mean \pm standard deviation of three independent experiments. ${ }^{\wedge} \mathrm{P}<0.01$ vs. healthy group; ${ }^{\#} \mathrm{P}<0.01$ vs. entecavir group; ${ }^{\square} \mathrm{P}<0.01$ vs. $10 \% \mathrm{mXCHD}$ group. $\mathrm{mXCHD}$, modified Xiaochaihu decoction.

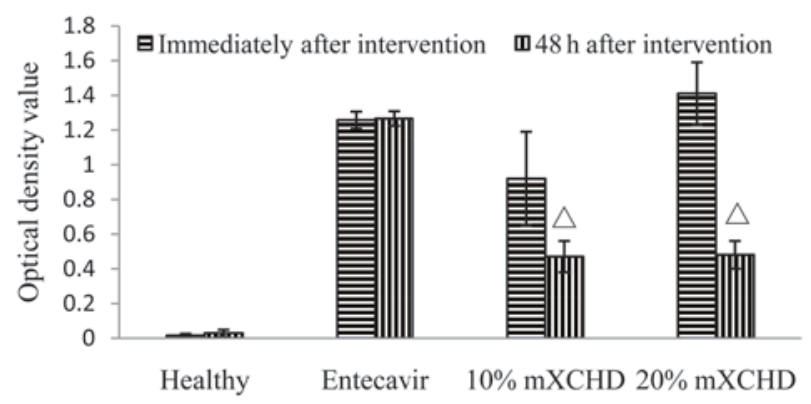

Figure 2. Effect of $\mathrm{mXCHD}$ serum on the concentration of HBsAg in the supernatant of HepG2.2.15 cells. The HepG2.2.15 cells were treated with corresponding serum, and the concentration of HBsAg in the supernatant of HepG2.2.15 cells was determined using an enzyme-linked immunosorbent assay immediately and $48 \mathrm{~h}$ following intervention. The data are presented as the mean \pm standard deviation of three independent experiments. Between the groups, a paired t-test was used to compare the concentration immediately and $48 \mathrm{~h}$ following intervention, ${ }^{\Delta} \mathrm{P}<0.01$, vs. immediately. mXCHD, modified Xiaochaihu decoction; HBsAg, hepatitis B surface antigen.

level of STAT3 in the 20\% mXCHD group was highest. These results suggested that $\mathrm{mXCHD}$ serum promoted the mRNA expression of STAT3.

Effect of $m X C H D$ serum on the protein expression levels of JAK2 and STAT3 in HepG2.2.15 cells. As shown in Fig. 4A and B, the protein expression levels of JAK2 and STAT3 were similar to their respective mRNA levels (Fig. 3) following treatment for $48 \mathrm{~h}$. No significant differences were observed in the protein expression levels of JAK2 among the four groups. The protein expression level of STAT3 in the 20\% mXCHD group was significantly higher, compared with that in the healthy group $(\mathrm{P}<0.05)$.

\section{Discussion}

CHB is a major disease, which affects millions of individuals. The immune response induced by HBV is the primary mechanism contributing to liver cell injury and inflammation. The aims of current treatment for CHB are to achieve the sustained suppression of HBV replication, remission of hepatic

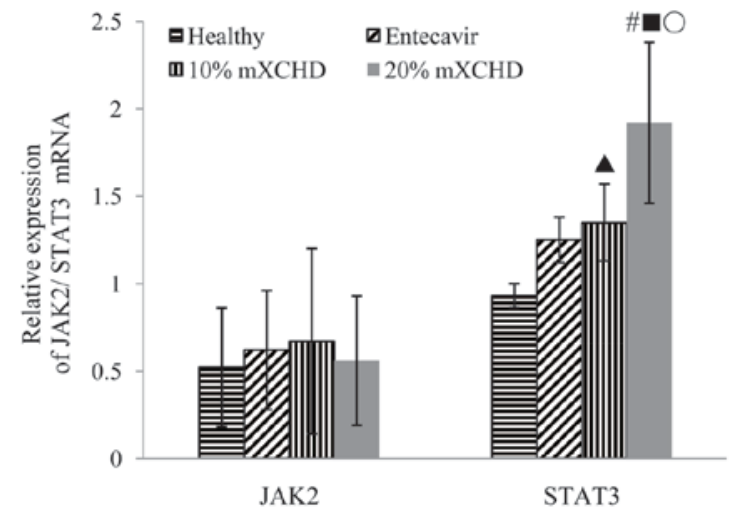

Figure 3. Effect of mXCHD serum on the mRNA expression levels of JAK2 and STAT3 in HepG2.2.15 cells. Following treatment for $48 \mathrm{~h}$, the cells were collected, and the mRNA levels of JAK2 and STAT3 were determined using reverse transcription-quantitative polymerase chain reaction analysis. $\beta$-actin was used as the internal control. The data are presented as the mean \pm standard deviation of three independent experiments. ${ }^{\wedge} \mathrm{P}<0.05$ and ${ }^{\#} \mathrm{P}<0.01$ vs. healthy group; ${ }^{-\mathrm{P}}<0.01$, vs. entecavir group; ${ }^{\circ} \mathrm{P}<0.01$, vs. $10 \% \mathrm{mXCHD}$ group. mXCHD, modified Xiaochaihu decoction; JAK2, Janus kinase 2; STAT3, signal transducer and activator of transcription 3 .

A

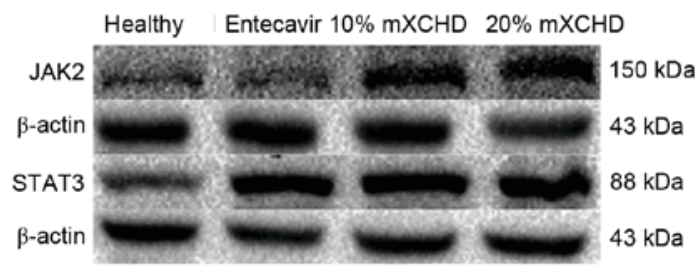

B

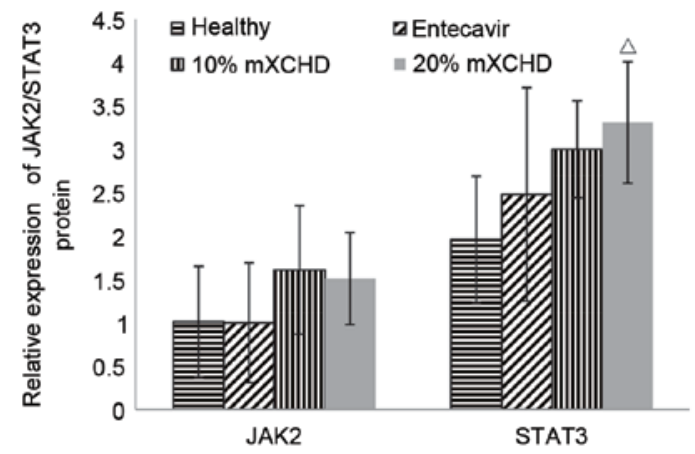

Figure 4. Effect of mXCHD serum on the protein expression levels of JAK2 and STAT3 in HepG2.2.15 cells. Following treatment with mXCHD serum, entecavir serum and healthy control serum for $48 \mathrm{~h}$, the cells were collected. The protein levels of JAK2 and STAT3 were determined using western blot analysis. $\beta$-actin was used as the internal control. (A) Representative images of the results ofwestern blot analysis. (B) Data are presented as the mean \pm standard deviation of three independent experiments. ${ }^{\Delta} \mathrm{P}<0.05 \mathrm{vs}$. healthy group. mXCHD, modifiedXiaochaihu decoction; JAK2, Janus kinase 2; STAT3, signal transducer and activator of transcription 3 .

inflammation, necrosis and fibrosis, and prevention of cirrhosis and HCC. A clinical cure for CHB has always been the aim of clinicians, involving a sustained virological response, the disappearance of HBsAg, normalizing of ALT levels, and pathological improvements in liver histology (24). Antiviral treatment has progressed in previous years, however, its application remains limited due to its high cost, prolonged therapy, frequent relapse following therapy cessation, and various side effects (25). As investigations of traditional Chinese medicine have progressed, the identification of drugs and therapies from 
TCMs with high efficiency, low toxicity and anti-HBV effects has been a focus of interest in medicine (26).

XCHD, derived from the classic TCM described in the Treatise on Febrile Diseases (27) has shown positive effects in the treatment of CHB in China, and it is a classic treatment for promoting bile flow. Bupleurum root and Scutellaria root are the core paired-component of XCHD. These two herbs have notable effects against infection and have antipyretic effects. There are other herbs in XCHD, including, Pinellia ternate and ginger, which can regulate gastrointestinal function. In addition, ginseng, Ziziphi jujubae and liquorice root can improve immunity. Qin et al (6) reported that, according to the methods of a systematic review, XCHD appeared to be effective at improving liver function and in the clearance of serum HBV markers in patients with $\mathrm{CHB}$. XCHD can regulate the immune response, improve suppression and clearance of viruses, and alleviate liver inflammation, and has an antifibrotic effects in the liver.

mXCHD contains Chinese thorowax root, Scutellaria baicalensis, Pinellia ternate, ginger, ginseng, Ziziphi jujubae, liquorice root, Phyllanthus urinaria, Largehead atractylodes rhizome, Poria cocos, white peony root and Fructus schisandrae. Modern pharmacology indicates that Phyllanthus urinaria possesses significant anti-HBV and anticancer activities, in addition to hepatoprotective effects. It is used primarily for the treatment of $\mathrm{HBV}$, and infection of the intestinal and urinary systems. Largehead atractylodes rhizome, Poria cocos, white peony root and Fructus schisandrae have hepatoprotective and antifibrotic effects (28). In the present study, HepG2.2.15 cells were cultured with the sera of patients treated with $\mathrm{mXCHD}$. Following treatment with the drug-containing serum for $48 \mathrm{~h}$, the cell viability, level of HBsAg, and expression levels of JAK2 and STAT3 of the JAK/STAT signaling pathway were detected.

Serum pharmacology is a novel method used to investigate traditional Chinese herbs. This technique overcomes the various disadvantages of applying drugs directly to cells. Following the oral administration of traditional Chinese herbs, various ingredients are absorbed into the blood through the gastrointestinal tract and are transformed into bioactive ingredients. Cells treated with serum containing TCMs in vitro provide conditions similar to those of cells found in vivo. Therefore, serum pharmacology experiments on Chinese herbal medicines performed in vitro may produce results with reliable consistency to corresponding experiments in vivo. In the majority of associated investigations into serum pharmacology, experimental animals, including rats and rabbits, are administered with the drug through their feed, and animal serum containing the drug is used to treat cells in culture in vitro. In the present study, human serum containing the drug was used under the preconditions of medical ethics approval and provision of informed consent. Drugs may produce novel active substances or stimulate the body to produce other active substances by metabolism following absorption. Therefore, theresults of adding the drug-containing serum in vitro are similar to those observed in vivo, particularly for Chinese herbs. Following oral absorption and metabolism of the anti-HBV TCM compound, the human serum containing the drug was added to the HepG2.2.15 cell culture, to more closely resemble the real status of drug metabolism in vivo.

In the present study, the proliferation of HepG2.2.15 cells was detected using an MTT assay following treatment with a range of concentrations of mXCHD serum for $48 \mathrm{~h}$. The results demonstrated that serum containing $\mathrm{mXCHD}$ was not toxic towards the cells, and it increased cell activity. Without drug intervention, the level of HBV in the supernatant of cell cultures increased with proliferation of the HepG2.2.15 cells. The $\mathrm{mXCHD}$-containing serum inhibited the expression of HBsAg at 10 and 20\%. Following intervention with mXCHD, normal growth of the HepG2.2.15 cells was maintained with no effect on cell proliferation, and the HBsAg content of HBV in the supernatant was also reduced. This indicated that HBV was effectively suppressed, which is consistent with the results expected in the clinical treatment of $\mathrm{CHB}$. As drug-containing serum from $\mathrm{HBV}$-infected patients was used for cell culture in the present study, the HBsAg concentration in the supernatant of the cell cultures in the mXCHD group were not only from the HepG2.2.15 cells, but also the human drug-containing serum of the patients with $\mathrm{CHB}$. There was no $\mathrm{HBV}$ or $\mathrm{HBs} \mathrm{Ag}$ in the sera of healthy volunteers, and their sera was used in one of the cell groups as a healthy control group. The effect of mXCHD on HBsAg was analyzed by comparing the changes in the level of HBsAg prior to and following treatment with 10 and $20 \%$ mXCHD-containing serum.

The JAK2/STAT3 signaling pathway transmits information from extracellular chemical signals to the nucleus, resulting in DNA transcription and the expression of genes involved in immunity, proliferation, inflammation, apoptosis and oncogenesis. The protein expression levels of several members of this pathway can be observed in liver tissues. These proteins are also involved in the wound-healing process in the liver. The liver has a regenerative function, in which the proliferative and regenerative function of hepatocytes promote repair of the injured liver. It has been shown that STAT3 is closely associated with the liver. With further investigations, the importance of STAT3 in the protection of the liver is likely to be gradually elucidated. STAT3 has notable anti-apoptotic and mitogenic abilities, and it can upregulate the expression of several genes associated with cell survival and proliferation. When liver cells are damaged, the expression of STAT3 increases following acute stress, the binding force to DNA strengthens, and the expression of Cyclin D1 is activated directly or indirectly. Cell mitosis then accelerates and stimulates liver cell proliferation (29-36).

In the present study, the mRNA and protein expression levels of STAT3 in cells were significantly upregulated by culture in serum containing $\mathrm{mXCHD}$, whereas those of JAK2 were unaffected. It was hypothesized that $\mathrm{mXCHD}$ can promote the upregulation of STAT3, and the latter is involved in the wound-healing process in the liver. The promotion of the proliferation and regeneration of hepatocytes through the JAK2/STAT3 signaling pathway may be one of the important mechanisms underlying the effect of $\mathrm{mXCHD}$ against $\mathrm{CHB}$. The JAK2/STAT3 signaling pathway, particularly STAT3, has a regulatory role in protection of the liver, which merits further investigation.

In conclusion, the present study demonstrated that $\mathrm{mXCHD}$ not only inhibited HBV, but also stimulated hepatocyte proliferation by upregulating the expression of STAT3. In the present study, the two detection time points of 48 and $144 \mathrm{~h}$ post-drug intervention were used. Due to limited funding, the extent of the experiments was limited. Therefore, further discussions 
and investigations are required, with the inclusion ofadditional time points for detection. The data obtained improves understanding of the effects and mechanisms of mXCHD in the treatment of CHB. However, which of the components of this herbal medicine contribute to these effects remains to be elucidated. Therefore, further investigations of the individual components of $\mathrm{mXCHD}$ are required in the future.

\section{Acknowledgements}

The present study was supported by the National Natural Science Foundation of China (grant no. 81403331) and the Natural Science Foundation of Fujian Province (grant no. 2014J01363).

\section{References}

1. World Health Organization: Guidelines for the prevention, care and treatment of persons with chronic hepatitis B infection. Geneva: WHO: 10-11, 2015.

2. Varbobitis I and Papatheodoridis GV: The assessment of hepatocellular carcinoma risk in patients with chronic hepatitis B under antiviral therapy. Clin Mol Hepatol 22: 319-326, 2016.

3. Intaraprasong P, Siramolpiwat S and Vilaichone RK: Advances in management of hepatocellular carcinoma. Asian Pac J Cancer Prev 17: 3697-3703, 2016.

4. Liaw YF, Kao JH, Piratvisuth T, Chan HL, Chien RN, Liu CJ, Gane E, Locarnini S, Lim SG, Han KH, et al: Asian-Pacific consensus statement on the management of chronic hepatitis B: A 2012 update. Hepatol Int 6: 531-561, 2012.

5. Tsai MC, Chen CH, Hu TH, Lu SN, Lee CM, Wang JH and Hung $\mathrm{CH}$ : Long-term outcomes of hepatitis B virus-related cirrhosis treated with nucleos (t)ide analogs. J Formos Med Assoc 115: 883-889, 2016.

6. Qin XK, Li P, Han M and Liu JP: Xiaochaihu Tang for treatment of chronic hepatitis B: A systematic review of randomized trials. Zhong Xi Yi Jie He Xue Bao 8: 312-320, 2010 (In Chinese).

7. Zhao F, An LF, Ma YQ and Yang KF: Efficacy of singly Chinese herbal drugs for hepatitis B virus in vitro and in vivo: A systematic review. Chinese Traditional Patent Medicine (Chin) 37: 2282-2285, 2015 (In Chinese).

8. Bai Y, Xia FN, Zhou SH, Yu KH and Liu JH: Regulating effect of traditional Chinese medicines for Enh II and core promoter of hepatitis B virus. Lishizhen Medicine and Materia medica Research (Chin) 26: 1534-1536, 2015 (In Chinese).

9. Wang Y: Effect of Xiaochaihu decoction combined with western medicine on liver function and HBV DNA copies in patient with chronic hepatitis B. Journal of New Chinese Medicine (Chin) 48: 74-76, 2016 (In Chinese).

10. Chen DD and Gong ZJ: The clinical study of Xiaochaihu decoction in treatment of chronic hepatitis B patients with liver fibrosis. Modern Journal of Integrated Traditional Chinese and Western Medicine (Chin) 20: 3928-3929, 2011 (In Chinese).

11. Zhao CH: Clinical observation on 40 cases of $\mathrm{HBeAg}$ - positive chronic hepatitis B treated with modified Xiaochaihu decoction combined with adefovior. Henan Traditional Chinese Medicine (Chin) 34: 1924-1925, 2014 (In Chinese).

12. Wang MH, Zheng DR and Cheng Q: Clinical Research of modified Xiaochaihu decoction combined with adefovior in treatment of chronic hepatitis B patients. Journal of Community Medicine (Chin) 12: 30-31, 2014 (In Chinese).

13. Xiao-qiu Liu, Xiao-jian $\mathrm{Hu}$, Hong-Xing $\mathrm{Xu}$ and Xiao-Ying Zeng: Xiaochaihu decoction attenuates the vicious circle between the oxidative stress and the ALP inactivation through LPS-catecholamines interactions in gut, liver and brain during $\mathrm{CCI}_{4}+$ ethanol-induced mouse HCC. BMC Complement Altern Med 13. 375, 2013.

14. Liu XB, Wang J, Zhang QQ, Liu T, Dang TM and Cao YM: The protective effect of XD in ConA-induced liver injury. Xi Bao Yu Fen Zi Mian Yi Xue Za Zhi 26: 1193-1194, 2010 (In Chinese).

15. Li J, Xie M and Gan Y: Effect of Xiaochaihu decoction and different herbal formulation of component on inhibiting $\mathrm{H} 22$ liver cancer in mice and enhancing immune function. Zhongguo Zhong Yao Za Zhi 33: 1039-1044, 2008 (In Chinese).
16. Sun MY, Xie M, Zhang N, Yi L and Wang S: Effect of xiaochaihu decoction and different herbal formulations of its components on cytokines of carrageenan induced pleuritis in rats. Zhongguo Zhong Xi Yi Jie He Za Zhi (Chin) 24: 628-631, 2004 (In Chinese).

17. Liu Z, Xiong $M$ and Zhang H: Experimental study on inhibitory effect of xiaochaihu decoction on duck hepatitis B virus. Zhongguo Zhong Xi Yi Jie He Za Zhi 20: 853-855, 2000 (In Chinese).

18. Sun XH, Wang ZL and Liu ZJ: Effect of modified Xiaochaihu decoction on HBV-DNA levels in sera and liver tissue in transgenic mice. Chinese Journal of Integrated Traditional and Western Medicine on Digestion (Chin) 19: 91-93, 2011 (In Chinese).

19. Chinese Society of Hepatology and Chinese Society of Infectious Diseases, Chinese Medical Association: The guideline of prevention and treatment for chronic hepatis B (2010 version). Zhonghua Gan Zang Bing Za Zhi 19: 13-24, 2011 (In Chinese).

20. The Internal Medicine Department Committee of Liver Disease in Chinese Traditional Chinese Medicine Association: TCM syndrome differentiation standards of Viral hepatitis (Trial). Journal of Traditional Chinese Medicine (Chin) 5: 39-40, 1992 (In Chinese).

21. World Medical Association: World Medical Association Declaration of Helsinki: Ethical principles for medical research involving human subjects. JAMA 310: 2191-2194, 2013.

22. Chinese Pharmacopoeia Commission: Pharmacopoeia of the People's Republic of China (volume 4, 2015 version). Beijing: China Medical Science Press: 7-151, 2015 (In Chinese).

23. Livak KJ and Schmittgen TD: Analysis of relative gene expression data using real-time quantitative PCR and the 2(-Delta Delta C (T)) method. Methods 25: 402-408, 2001.

24. Boucle S, Bassit L, Ehteshami M and Schinazi RF: Toward elimination of Hepatitis B virus using novel drugs, approaches and combined modalities. Clin Liver Dis 20: 737-749, 2016.

25. Jeng WJ, Chen YC, Sheen IS, Lin CL, Hu TH, Chien RN and Liaw YF: Clinical relapse after cessation of tenofovir therapy in Hepatitis B e antigen-negative patients. Clin Gastroenterol Hepatol 14: 1813-1820, 2016.

26. Xia J, Inagaki Y, Song P, Sawakami T, Kokudo N, Hasegawa K, Sakamoto $\mathrm{Y}$ and Tang W: Advance in studies on traditional Chinese medicines to treat infection with the hepatitis B virus and hepatitis C virus. Biosci Trends 10: 327-336, 2016.

27. Xiong MQ, Wang QG, Guan QZ, et al: Science of Exogenous Febrile Diseases. Beijing: China Press of Traditional Chinese Medicine: 263-272, 2003 (In Chinese).

28. Gu JP, Wang CL, Zhang FF, et al: Pharmacology of Traditional Chinese Medicine. Shanghai: East China University of Science and Technology Press: 110-229, 2015 (In Chinese).

29. Li L, Lei QS, Zhang SJ, Kong LN and Qin B: Suppression of USP18 potentiates the anti-HBV activity of interferon Alpha in HepG2.2.15 cells via JAK/STAT signaling. PLoS One 11: e0156496, 2016.

30. Zhu X, Xie C, Li YM, Huang ZL, Zhao QY, Hu ZX, Wang PP, Gu YR, Gao ZL and Peng L: TMEM2 inhibits hepatitis B virus infection in HepG2 and HepG2.2.15 cells by activating the JAK-STAT signaling pathway. Cell Death Dis 7: e2239, 2016.

31. Guan SH, Yang K, Lu MJ, Lu YP and Yang DL: The influence of HBV and its antigens on the expressions of JAK-STAT signal transduction pathway molecules and antiviral proteins of IFN alpha. Zhonghua Gan Zang Bing Za Zhi 19: 440-444, 2011 (In Chinese).

32. Bock CT, Toan NL, Koeberlein B, Song le H, Chin R, Zentgraf H, Kandolf R and Torresi J: Subcellular mislocalization of mutant hepatitis B X proteins contributes to modulation of STAT/SOCS signaling in hepatocellular carcinoma. Intervirology 51: 432-443, 2008.

33. Churin Y, Roderfeld M, Stiefel J, Würger T, Schröder D, Matono T, Mollenkopf HJ, Montalbano R, Pompaiah M, Reifenberg K, et al: Correction: Pathological impact of hepatitis B virus surface proteins on the liver is associated with the host genetic background. PLoS One 10: e0127375, 2015.

34. Li W, Liang X, Kellendonk C, Poli V and Taub R: STAT3 contributes to the mitogenic response of hepatocytes during liver regeneration. J Biol Chem 277: 28411-28417, 2002.

35. Schwabe RF, Bradham CA, Uehara T, Hatano E, Bennett BL, Schoonhoven R and Brenner DA: c-Jun-N-terminal kinase drives cyclin D1 expression and proliferation during liver regeneration. Hepatology 37: 824-832, 2003.

36. Chen XL, Meng Q and Liu KX: Role of STAT3 signaling pathway in repair of liver injury. World Chinese Journal of Digestology (Chin) 22: 1051-1057, 2014 (In Chinese). 